\title{
Os mitos fundadores de Brasília na imprensa internacional
}

\section{The founding myths of Brasilia in the international press}

Graziane de Andrade Souza Silva ${ }^{1}$

\section{Resumo}

Tendo como fonte bibliográfica o livro Do concreto ao papel, lançado por ocasião da comemoração dos 50 anos de Brasília, o presente artigo se propõe a analisar a visão da imprensa internacional acerca da construção e da inauguração de Brasília em 21 de abril de 1960. A presente análise busca ressaltar como foram apropriados os discursos mitológicos sobre a fundação da nação brasileira e a busca por uma identidade, tanto por Juscelino $\mathrm{Ku}$ bitschek quanto pela imprensa internacional, principalmente na América e Europa, para justificar a construção da nova capital e servindo para a busca de uma identidade local.

Palavras-chave: Mitos fundadores. Identidade. Imprensa. Brasília.

\begin{abstract}
As a bibliographic source, the book Do concreto ao papel, which was released on the commemoration of 50 years of Brasilia, the present article proposes to analyze the vision of the international press about the construction and the inauguration of Brasilia in April 21, 1960. This analysis seeks to highlight how the mythological speeches about the foundation of the Brazilian nation and the search for an identity were appropriated by Juscelino Kubitschek and by the international press, especially in America and Europe, in order to justify the construction of the new capital and also serving for the search of a local identity.
\end{abstract}

Keywords: Founding myths. Identity. Press. Brasília.

\footnotetext{
Licenciada em História pelo UniCEUB e pósgraduanda em História, Sociedade e Cidadania pela mesma instituição. Atua como professora de Ensino Médio na rede particular de ensino de Belo Horizonte - MG. Endereço eletrônico: grazydeandrade@hotmail.com.
} 


\section{Introdução}

Os mitos fundadores de determinadas sociedades são fundamentais para a formação da identidade de seu povo. Mas a tarefa de fazer com que o mito se propague e seja aceito leva tempo e tem que ser constituída por elementos que propiciem aos indivíduos o reconhecimento de si mesmos dentro do próprio mito.

A constituição da nação remete a pessoas que nasceram em um mesmo lugar e são originárias de uma mesma cultura. Essa ideia surge no Império Romano e se reatualiza com o advento do Iluminismo e da formação do Estado-nação moderno. Para Anderson, a definição de nação pode ser:

Uma comunidade política imaginada - e imaginada como sendo intrinsecamente limitada e, ao mesmo tempo, soberana.

Ela é imaginada porque mesmo os membros da mais minúscula das nações jamais conhecerão, encontrarão, ou sequer ouvirão falar da maioria de seus companheiros, embora todos tenham em mente a imagem viva da comunhão entre eles (ANDERSON, 2008, p. 32).

Para que esse sentimento de comunhão aflore, é preciso criar símbolos que façam sentido a todos os membros da sociedade e que despertem em seus habitantes um sentimento fraterno que os una em prol da nação. Tais símbolos remetem a um sentimento que vai além das aparências, reforçam exclusões e constroem verdades absolutas. Dessa forma, a noção de comunidades imaginadas de Anderson nos mostra o valor do mito na formação da sociedade moderna.

No processo de pertencimento a uma nação, o mito é parte fundamental para o reconhecimento dos indivíduos que integram uma comunidade como "filhos" de uma mesma nação. Segundo Fitz (2005, p. 15),

O mito, nas sociedades em que se desenvolve, é tido como uma verdade absoluta transmitida por seus 'fundadores' em um tempo 'anterior ao nosso tempo, adquirindo, portanto, foro de credibilidade social.

Os mitos fundadores fazem parte da constituição de uma identidade comum e, no caso do Brasil, esses mitos foram fundamentais, pois são "[...] uma solução imaginária para tensões, conflitos e contradições que não encontram caminhos para serem resolvidos no nível da realidade" (CHAUÍ, 1996, p. 9). Por esse motivo, tanto um morador de uma favela como um magnata político têm os mesmos sentimentos de pertença ao ouvir o Hino
Nacional ou ao assistir a uma partida de futebol da copa do mundo.

No caso de Brasília, os mitos fundadores foram de suma importância para a aceitação do grande empreendimento do presidente do Brasil, à época, Juscelino Kubitschek, para a transferência de todo poder executivo nacional para o centro do país. Os mitos fundadores do Brasil foram aplicados ao nascimento da nova capital, facilitando, dessa forma, a assimilação de tamanha empreitada na imprensa internacional, a inauguração da capital federal do Brasil, o que reforça ainda mais a ideia dos mitos fundadores do Brasil e de Brasília entrelaçados e se compondo.

Neste artigo, é feita uma breve análise das notícias da inauguração de Brasília em 21 de abril de 1960, na imprensa internacional, e como a imagem mítica da sua construção é reforçada nesses artigos. Nesta análise, utilizamos como recursos comparativos os mitos fundadores do Brasil e sua aplicação na inauguração de Brasília pelo presidente Jucelino Kubitschek.

\section{Mitos fundadores e a construção da identida- de do Brasil}

A construção dos mitos fundadores de uma nação é de suma importância para o reconhecimento e sentimento de pertencimento a um determinado território. De acordo com Marilena Chauí:

\begin{abstract}
O mito fundador oferece um repertório inicial de representações da realidade e, em cada momento da formação histórica, esses elementos são reorganizados tanto do ponto de vista de sua hierarquia interna (isto é, qual o elemento principal que comanda os outros) como da ampliação de seu sentido (isto é, novos elementos vêm se acrescentar ao significado primitivo). Assim, as ideologias, que necessariamente acompanham o movimento histórico da formação, alimentam-se das representações produzidas pela fundação, atualizando-as para adequálas à nova quadra histórica. É exatamente por isso que, sob novas roupagens, o mito pode repetir-se indefinidamente (CHAUÍ,1996, p. 10).
\end{abstract}

Até pouco tempo depois da Independência do Brasil, em 1822, os indivíduos pertencentes a esse vasto território não possuíam nenhum sentimento de pertencimento a uma nação, ou identidade comum que os representasse. Havia muito mais um sentimento regionalista do que nacionalista. Para a recém-formada Nação brasileira, um dos maiores desafios era manter a unidade ter- 
ritorial e construir um tipo de identidade que se pudesse chamar brasileira.

Segundo Decca (2002, p. 8), “[...] a identidade de um grupo forma-se normalmente por sinais externos e por um conjunto de símbolos e valores a partir dos quais se opera uma identificação". Desse modo, os símbolos que constituem uma nação podem ser facilmente identificados pelos indivíduos que a constituem. A criação de uma identidade no Brasil se fazia extremamente necessária durante o século XIX, quando havia a necessidade de se criar algum sentimento de pertencimento a uma mesma nação entre os habitantes do vasto território do país. De acordo com Guimarães:

[...] é no bojo de consolidação do Estado Nacional que se viabiliza um projeto de pensar a história brasileira de forma sistematizada. A criação, em 1838, do Instituto Histórico e Geográfico Brasileiro (IHGB) vem apontar em direção à materialização deste empreendimento, que mantém profundas relações com a proposta ideológica em curso. Uma vez implantado o Estado Nacional, impunha-se como tarefa o delineamento de um perfil para a 'Nação Brasileira', capaz de lhe garantir uma identidade própria no conjunto mais amplo das 'Nações', de acordo com os novos princípios organizadores da vida social do século XIX (GUIMARÃES, 1988, p. 6).

A fundação do Instituto Histórico e Geográfico Brasileiro, em 1838, foi de crucial importância para se forjar uma identidade nacional tal como era de interesse do Estado monárquico brasileiro. Embora sua fundação se dê como um órgão independente do Estado imperial e tenha como proposta coletar documentos históricos, sistematizá-los e empreender ações para o conhecimento do território nacional, logo se constituiu como legitimador do poder nacional, auxiliando o Estado na construção de uma história e no levantamento dos recursos e potencialidades do território brasileiro.

O projeto historiográfico do IHGB é de exaltação da história nacional, dos nossos heróis, dos acontecimentos oficiais que transformaram a nossa nação e a modernizaram. $\mathrm{O}$ historiador tinha o dever nacional de exaltar nossos líderes políticos mais célebres, assim como seus maiores feitos. De acordo com artigo publicado na revista do IHGB, em 1847:

Deve o historiador, se não quiser que sobre ele carregue grave e dolorosa responsabilidade, pôr a mira em satisfazer aos fins políticos a moral da história. Com os sucessos do passado ensinará à geração presente em que consiste a sua verdadeira felicidade, chamando-a a um nexo comum [...] (GUIMARÃES, 1988, p. 17).
O primeiro, dentro do IHGB, a fornecer uma diretriz para a escrita da história nacional, e o vencedor do concurso destinado a premiar o trabalho que apresentasse a melhor proposta para a escrita da história do Brasil, foi o naturalista e viajante Karl Friedrich Philip von Martius $^{2}$. Em sua monografia, intitulada Como se deve escrever a história do Brasil, premiada com o primeiro lugar no concurso, Martius propôs uma história nacional que exaltasse as três raças que formam a população do Brasil: o português, o índio e o negro, contribuindo, dessa forma, para a formação do mito da democracia racial brasileira.

De acordo com Martius:

[...] devia ser um ponto capital para o historiador reflexivo mostrar como no desenvolvimento sucessivo do Brasil se acham, estabelecidas as condições para o aperfeiçoamento de três raças humanas, que nesse país são colocadas uma ao lado da outra, de uma maneira desconhecida na história antiga (MARTIUS, 1845 apud GUIMARÃES, 1988, p. 18).

A ideia da construção de uma identidade nacional vai passar por questões como a constante exaltação à colonização portuguesa e aos heróis do descobrimento, da independência, ou seja, dos grandes acontecimentos da nação, pela busca de uma unidade territorial, de centralização de poder e, por fim, pelas raças que constituíram a nação brasileira.

"A escola passa a ter papel fundamental na difusão dos mitos e dos símbolos nacionais ainda durante o Império, com a nomeação de Gonçalves Dias para a cadeira de História do Brasil do Colégio D. Pedro II" (FITZ, 2005, p. 21).

O Colégio D. Pedro II, fundado em 02 de dezembro de 1837, foi o primeiro colégio de instrução secundária oficial do Brasil, caracterizando-se como importante elemento de construção do projeto civilizatório do Império, de fortalecimento do Estado e de formação da nação brasileira. Como agência oficial de educação e cultura, cocriadora das elites condutoras do país, o Imperial Colégio foi criado para ser modelo da instrução pública secundária do Município da Corte e demais províncias.

\footnotetext{
2 Karl Friedrich Philip von Martius, alemão nascido em 1794, veio para o Brasil em 1817 na comitiva de Leopoldina, grãduquesa austríaca, que chegava ao Brasil para se casar com D. Pedro. No Brasil, Von Martius desenvolveu estudos antropológicos (etnologia), botânicos e de metodologia histórica e científica.
} 
De acordo com Marilena Chauí (1996, p. 10),

[...] as ideologias, que necessariamente acompanham o movimento histórico da formação, alimentam-se das representações produzidas pela fundação, atualizando-as para adequá-las à nova quadra histórica.

Não obstante, durante toda a história do Brasil, houve uma busca por elementos novos que se adequassem às mudanças que estavam acontecendo, levando em conta uma maior identificação mitológica com a população.

Outro grande problema surge com o advento da República, quando novos atores serão colocados como heróis nacionais para reafirmarem as práticas do Estado Republicano que se formava. Era preciso romper com a antiga tradição da exaltação aos heróis de origem portuguesa para dar espaço ao modernismo trazido pelo modelo republicano de governo, pois:

O processo de construção de uma nação republicana em fins do século XIX exigia, pois, a formulação de um passado que sacralizasse essa nação e seus lugares de identificação -'os lugares da memória' -, marcando um espaço simbólico nacional-republicano. Heróis como Tiradentes, símbolos como a bandeira, o hino nacional e celebrações do calendário cívico, foram articulados nos primeiros anos da República, anos de invenções de tradições. [...] Os positivistas destacaram-se nessa tarefa: detentores de uma metodologia 'científica', conduziram um intenso trabalho de reconstrução da memória nacional, que procurava situar a República na nacionalidade (MOTTA, 1992, p.13).

Mesmo com a mudança de governo da Monarquia para a República, os mecanismos utilizados para a construção dos novos mitos foram os mesmos, ou seja, algo que reforçava a autoridade do Estado e que vinha sempre acompanhado de um discurso civilizador e progressista.

\section{Utilização dos mitos fundadores na constru- ção de Brasília}

De modo geral, os mitos fundadores do Brasil encontram-se em alguns elementos que, além da noção de "democracia racial", conformam a visão que temos de nosso país: cumpre do ponto de vista de uma teofania (revelação de Deus no tempo) e uma epifania (revelação da verdade divina no tempo) ao mesmo tempo em que se revela profética (cumprimento da vontade divina) e soteriológica (promessa de redenção no tempo). Essa história, de caráter providencialista, passa a reforçar as ideias de que o Brasil é o país do futuro, que Deus teria escolhido o povo brasileiro como seu Povo Eleito, enfim, "Deus é brasileiro";

A ideia da sagração do governante, herdada do absolutismo e de matriz judaico-cristã. $\mathrm{O}$ governante possui dois corpos: o corpo físico humano e o corpo político, místico, imortal, divino que lhe é dado por Deus. Assim, o Estado antecede a própria sociedade e tem sua origem fora dela (CHAUÍ, 1996, p. 8).

Parte dos mitos de nossa história, como apresentados por Chauí (1996), foi mobilizada pelo presidente Juscelino Kubitschek para fazer com que a ideia da mudança da capital federal, do Rio de Janeiro, que era a sede do governo desde 1763, para o centro do país, fosse aceita pela ampla maioria dos brasileiros e principalmente para obter o apoio de uma elite que sabia o quanto pagaria por isso.

Todas as questões dos nossos mitos de fundação foram evocadas na ocasião da construção de Brasília por Juscelino Kubitschek. No dia da inauguração da nova capital, a sensação de extrema euforia do presidente e dos seus colaboradores foi relatada em grande parte do mundo.

A referência que se faz à natureza intocada, até então, pelos homens e a consequente elaboração da ideia de "vazio" demográfico na região, onde foi construída a capital, presente no discurso do presidente, é algo a ser pensado como parte do próprio mito fundador do Brasil. Mito que se manifesta na ideia da chegada do português, em 1500, para trazer luz e civilidade a espaços e povos que viviam abandonados e sem perspectiva futura. A construção da nova capital é vista como uma violação do sertão bruto, para gerar uma cidade comparada a um organismo vivo:

Não nos voltemos para o passado, que se ofusca ante esta profusa radiação de luz que outra aurora derrama sobre a nossa Pátria. Quando aqui chegamos, havia na grande extensão deserta apenas o silêncio e o mistério da natureza inviolada. No sertão bruto iam-se multiplicando os momentos felizes em que percebíamos tomar formas e erguer-se por fim a jovem Cidade. Vós todos, aqui presentes, a estais vendo, agora, estais pisando as suas ruas, contemplando os seus belos edifícios, respirando o seu ar, sentindo o sangue da vida em suas artérias (KUBITSCHEK, 1960). 
Outro ponto importante da relação entre os mitos fundadores do Brasil e de Brasília está na ideia de "democracia racial”. O presidente Juscelino Kubitschek faz questão de enfatizar a participação das diversas partes da população brasileira no seu projeto:

Viramos no dia de hoje uma página da História do Brasil. Prestigiado, desde o primeiro instante, pelas duas Câmaras do Congresso Nacional e amparado pela opinião pública, através de incontável número de manifestações de apoio, sinceras e autenticamente patrióticas, dos brasileiros de todas as camadas sociais que me acolhiam nos pontos mais diversos do território nacional, damos por cumprido o nosso dever mais ousado; o mais dramático dever.

$[\ldots]$

Mas no País inteiro sentimos raiar a grande esperança, a companheira constante em toda esta viagem que hoje concluímos; ela amparou-nos a todos, a mim e a essa esplêndida legião que vai desde Israel Pinheiro, cujo nome estará perenemente ligado a este cometimento, até ao mais obscuro, ao mais ignorado desses trabalhadores infatigáveis que tornaram possível o milagre de Brasília (KUBITSCHEK, 1960).

Nesse discurso, podemos perceber como Juscelino conclama todos os brasileiros à responsabilidade pela nova capital, quer seja no apoio dado ou no árduo trabalho da construção, todos são lembrados e chamados a fazer parte do sonho tornado realidade. Tal envolvimento contribui para o amplo apoio dos brasileiros à ideia de integrar um projeto tão grandioso, o que acarreta em uma nova identidade que se faz no reforço ao mito. Para Chauí:

O mito fundador oferece um repertório inicial de representações da realidade e, em cada momento da formação histórica, esses elementos são reorganizados tanto do ponto de vista da sua hierarquia interna (isto é, qual o elemento principal que comanda os outros) como da ampliação do seu sentido (isto é, novos elementos vêm se acrescentar ao significado primitivo) (CHAUÍ, 1996, p. 10).

A visão simbólico-religiosa (FITZ, 2005, p. 20) também é reforçada na ideologia mitológica de Brasília. Primeiro, pelo sonho de Dom Bosco, que revelava que "entre os paralelos 15 e 20 no lugar onde se criou um lago, nascerá uma civilização espetacular e acontecerá isso na terceira geração. Esta será a terra prometida”. Em segundo lugar, pelo próprio presidente que se refere ao assunto em seu discurso:

Somente me abalancei a construí-la quando de mim se apoderou a convicção de sua exeqüibilidade por um povo amadurecido para ocupar e valorizar plenamente no território que a Providência Divina lhe reservara. Nosso parque industrial e nossos quadros técnicos apresentavam condições e para traduzir no betume, no cimento e no aço as concepções arrojadas da arquitetura e do planejamento urbanístico moderno (KUBITSCHEK, 1960).

Percebemos então que, a cada trecho do discurso de Juscelino na inauguração, são mobilizados e lembrados elementos fundamentais da constituição do mito de formação do Brasil. O próprio presidente, inclusive, se coloca como agente principal desse sonho realizado, desse destino que se cumpriu com a inauguração. Segundo Chauí (1996, p. 83), “o governante possui dois corpos: o corpo físico humano e o corpo político, místico, imortal, divino que lhe é dado por Deus":

Dirigindo-me a todos os meus concidadãos, de todas as condições sociais, de todos os graus de cultura, que, dos mais longínquos rincões da Pátria, voltais os olhos para a mais nova das cidades que o Governo vos entrega, quero deixar que apenas fale o coração do Vosso Presidente.

Não vos preciso recordar, nem quero fazê-lo agora, o mundo de obstáculos que se afiguravam insuportáveis para que o meu Governo concretizasse a vontade do povo, expressa através de sucessivas constituições, de transferir a Capital para este planalto interior, centro geográfico do País, deserto ainda há poucas dezenas de meses (KUBITSCHEK, 1960).

\section{0 papel da imprensa no reforço ao mito da construção de Brasília}

A repercussão da inauguração da nova capital do Brasil, Brasília, na imprensa mundial foi muito grande. O caráter modernista do projeto de Oscar Niemeyer e de Lúcio Costa, colocando a nova cidade com a perspectiva de ser totalmente planejada e acessível a todos os brasileiros, foi comentado em vários jornais internacionais, com destaque para o caráter modernizador e civilizatório do empreendimento.

No jornal $A B C$ de Madri, saiu a seguinte notícia no dia 19/04/1960:

Brasília é o início de uma nova era, de uma ruptura e mutação de valores artísticos e humanos, uma revalorização audaz para um novo tipo de civilização que, para nós europeus, arraigados em moldes talvez demasiados arcaicos, poderá ser surpreendente, mas que suscita profunda admiração [...]. É inquestionável que este passo gigantesco dado pelo Brasil, ao decidir-se com denotado esforço povoar o interior de seu feroz 
território, há de levá-lo em curto prazo a um altíssimo nível de civilização e de prosperidade (DIAS, 2010, p. 19).

Já o jornal Berlingske Tidente, de Copenhague, em notícia do dia 21/04/1960, destacava:

A Meca da arquitetura moderna e planejamento urbano está sendo criada a 1.000 quilômetros do Rio de Janeiro. Oscar Niemeyer oferecerá à cidade o seu estilo [...]. O fato da escolha de uma nova capital (e aqui ainda há conversas sobre se criar uma cidade completamente nova e moderna) ocorre sem precedentes no mundo moderno. Temos que voltar à criação de Washington, em 1790, para encontrar similaridade com o que ocorre em Brasília (DIAS, 2010, p. 22).

Em 20/04/1960, em Milão, o Corriere Della Serra lançou o seguinte:

\section{AMANHÃ NASCERÁ BRASÍLIA, "CAPITAL DA ESPERANÇA"}

Grandiosos preparativos para a inauguração da moderníssima metrópole erguida em tempo recorde pela vontade de Kubitschek.

Estamos no Planalto Central para assistir ao nascimento de Brasília que, no dia 21 de abril, tornar-se-á a capital do Brasil. A cidade é o teorema de urbanismo demonstrado por Lúcio Costa, e um esforço plástico de Oscar Niemeyer (DIAS, 2010, p. 25).

Nos jornais da Suécia também se ressaltava o modernismo e a ousadia representada pela arquitetura e concepção urbanística da cidade. No Göteborgs Handels, de Gotemburgo, em 21/04/1960, podia-se ler:

\section{A CIDADE MAIS MODERNA DO MUNDO É INAUGURADA EM UM PLANALTO DESÉR- TICO}

No dia 21 de abril, inaugura-se a nova capital do Brasil. Esse é o gigantesco empreendimento civil ao estilo da cidade de Camberra na Austrália, mas superando-a em tamanho.

Aqui se construiu o alicerce de um centro econômico, cultural e administrativo para uma população de 62 milhões de brasileiros, utilizando-se toda a experiência da moderna arquitetura para que tal centro possa funcionar adequadamente em todos os sentidos (DIAS, 2010, p. 29).

O La Nación, de Buenos Aires, publicou em 21/04/1960 que:

[...] Seu projeto e a modernidade original da sua arquitetura correspondem a um estilo brasileiro. Para entendê-la, ao visitá-la é preciso se despojar de todo preconceito. Brasília é uma nova realidade, única. Seus arranha-céus já estão a serviço do homem, da vida, pois Brasília não tem a menor lembrança. Nada aconteceu ainda em Brasília, fora do prodígio de Brasília em si. Brasília está pronta para sua andança durante os séculos, pois a sua hora é ainda a que a chamou o Presidente Kubitschek ao pôr a pedra principal da nova capital da sua pátria: a da alvorada (DIAS, 2010, p. 56).

A religiosidade do evento da inauguração de Brasília foi amplamente discutida na mídia internacional. $\mathrm{O}$ aspecto teológico que sempre acompanhou a História do Brasil, também foi utilizado por Jucelino Kubitschek. Aspectos como a cruz, a primeira missa local, a mistura de pessoas de diversas classes na inauguração, até mesmo a escolha do representante do Papa João XXIII para celebrar a nossa missa inaugural esteve relacionada ao mito fundador do Brasil, pois foi um português o escolhido.

A Voz de Lisboa, em 22/04/1960, levou a seguinte notícia aos portugueses:

Papa concede Benção Apostólica e invoca abundantes graças a nação.

Voltado para a Cruz da Descoberta e da Primeira Missa, que Portugal nos confiou para este dia solene, agradeço a Deus com a maior humildade o que foi feito, disse o Presidente Juscelino Kubitschek no momento da inauguração (DIAS, 2010, p. 18).

O famoso jornal Le Monde, de Paris, em 22/04/1960 escreveu aos seus leitores:

Em missa à meia-noite de ontem em Brasília, aos pés da cruz diante da qual pai Henrique de Coimbra celebrou a primeira missa em 1500 e ao retumbar do hino nacional, o Papa saudou o povo brasileiro e o seu legado. Hoje, quintafeira, as Câmaras reunidas em sessão solene abrem-se na nova capital. Desfile de tropas vindas a pé do Rio de Janeiro e da Bahia, desfile das máquinas que construíram Brasília, concerto sinfônico e corridas. Nada faltará para marcar de forma digna o triunfo da grandeza (DIAS, 2010, p. 39).

Em Estocolmo, a inauguração de Brasília foi saudada, no dia 22/04/1960, pelo jornal Svenska Dagbladet:

\section{BRASÍLIA É PROCLAMADA CAPITAL EM SOLENE CERIMÔNIA RELIGIOSA.}

Nesta última quinta-feira, o mundo ganhou uma nova capital. A ainda inacabada cidade futurista de Brasília foi construída no coração da floresta brasileira, tornando-se a nova capital do país à meia noite ( 04 horas horário sueco). O evento foi acompanhado de pomposas cerimônias religiosas. [...].

Brasília foi proclamada capital com uma missa Católica Romana, celebrada pelo cardeal portu- 
guês, Manoel Gonçalves Cerejeira, enviado do Papa João XXIII (DIAS, 2010, p. 43).

No trecho acima, podemos perceber ainda a imagem existente do Brasil, no âmbito internacional, como um lugar composto por imensas florestas, assim como o encontraram os primeiros portugueses. No jornal londrino The Sunday Times, do mesmo dia, podemos encontrar uma chamada que também faz uso dessa imagem: "BRASÍLIA: A CAPITAL NA FLORESTA" (DIAS, 2010, p. 45).

Outro aspecto importante de se perceber para entendermos a associação de mitos brasileiros elaborados secularmente com os novos mitos brasilienses é a personificação do grande herói defensor do progresso e desbravador dos sertões na figura do então presidente Juscelino Kubitschek. Na imprensa internacional, o presidente Kubitschek é sempre lembrado como grande visionário, exímio explorador e homem cheio de coragem para enfrentar o interior, até então "um planalto desértico" (DIAS, 2010, p. 29), local escolhido para construir e transferir todo o governo para a nova capital.

Um exemplo de como Juscelino Kubitschek é visto pela imprensa mundial é o que coloca o jornal Helsingin Sanomat, de Helsinque, na Finlândia, no dia da inauguração de Brasília:

"Nós temos de conquistar nosso país, marchar rumo ao oeste, virar as costas ao mar, parar de olhar para o Atlântico..." declarou o Presidente do Brasil, Juscelino Kubitschek, quando começou a construção da nova capital, há uns três anos. Hoje, o Brasil olha para o interior, para o planalto do Estado de Goiás, onde Brasília a nova capital - começa a exercer a sua função [...] (DIAS, 2010, p. 30).

O L’Unità, de Milão, escreveu em 20/04/1960:

[...] Esta manhã, às $8 \mathrm{~h}$, a capital do Brasil deixará de ser o Rio de Janeiro, para ser uma nova cidade: Brasília, como havia decretado há apenas cinco anos atrás o Presidente da República Juscelino Kubitschek.

Por que uma capital nova? Porque agora se trata de empreender uma nova conquista, a do interior do país, potencialmente riquíssimo, mas ainda não explorado (DIAS, 2010, p. 36).

Outros jornais chamam Brasília "uma obra pessoal de Kubitschek" (DIAS, 2010, p. 20), construída com “coragem e audácia” (DIAS, 2010, p. 25) devido à personificação da construção de Brasília como algo que tivesse seu rosto impresso, o presidente que teve a coragem de criar uma cidade a partir do nada.
A partir das notícias analisadas, podemos levantar questões acerca de como a visão do outro, de quem está de fora do país, pode reforçar o mito de fundação de Brasília, uma vez que seu olhar é neutro em relação à cultura local. Dessa forma, a imprensa colaborou e ainda colabora para reforçar a ideia de uma identidade coletiva que não só é reconhecida internamente como por quem a observa.

\section{Considerações finais}

O material coletado para a análise feita pode nos mostrar como através da história os mitos se criam e recriam, na medida das necessidades internas de uma nação, o que serve para os mais variados fins.

Os conceitos de mito e de identidade coletiva caminham lado a lado uma vez que reforçam uma ideia coletiva de reconhecimento de um passado, de um presente e de um futuro comum aos indivíduos pertencentes a uma mesma nação.

Dessa forma, a utilização de mitos fundadores na formação do Estado brasileiro se coloca como necessária a uma nação que está nascendo e que tem um passado ao qual poucos se reconhecem como pertencentes.

De acordo com Fitz,

Os mitos profético-providencialistas e o enaltecimento dos governantes como salvadores da pátria propaga a ideia de uma nação pacífica, sem violência - política - seguramente conduzida. A invenção de tradições e a construção de mitos obliteram não somente o passado, mas lançam também uma cortina de fumaça sobre o presente. O passado não é usado para explicar ou compreender o presente, mas para justificálo (FITZ, 2005, p. 23).

Os mitos fundadores ainda foram utilizados para aceitação de um plano faraônico do presidente do Brasil, Juscelino Kubitschek, na construção de uma nova capital para o país, onde não havia "nada".

O presente artigo se propôs a uma breve análise da relação dos mitos fundadores brasileiros com os de Brasília, à luz da sua aceitação e justificação pela imprensa internacional. Mas o assunto é amplo e permite um longo debate sobre as consequências da criação dos mitos, ou seja, aquilo que o mito escamoteia - as desigualdades sociais, a exclusão, as vozes silenciadas etc. 


\section{Referências}

ANDERSON, Benedict. Comunidades imaginadas. São Paulo: Companhia das Letras, 2008.

CHAUÍ, Marilena. Brasil: mito fundador e sociedade autoritária. São Paulo: Fundação Perseu Abramo, 1996.

DECCA, Edgar Salvadori de. Cidadão, mostre-me a identidade! Caderno Cedes, Campinas, n. 58, p. 7-20, dez., 2002. Disponível em: $<$ http://www.cedes.unicamp. br/caderno/cad/cad58.htm >. Acesso em: 20 mar. 2009.

DIAS, Etevaldo (Org.). Do concreto ao papel: o nascimento de Brasília na imprensa mundial. Brasília: Santafé Ideias e Comunicação, 2010.

FITZ, Ricardo Arthur. Brasil: os mitos fundadores da nacionalidade. Ciências \& Letras, Porto Alegre, n. 37, p. 9-24, jan/jun. 2005. Disponível em: <http://www1.fapa. com.br/cienciaseletras/php/cienciaseletras.php?pag $=4>$. Acesso em: 09 mar. 2009.
GUIMARÃES, Manoel L. S. Nação e civilização nos trópicos: O IHGB e o projeto de uma História Nacional. Estudos Históricos, Rio de Janeiro, n. 1, 1988.

KUBITSCHEK, Juscelino. Discurso oficial da Inauguração da Capital Federal - Brasília. 21/04/1960. Disponível em: http://www.franklinmartins.com.br/ estacao_historia_artigo.php?titulo=discurso-de-jk-nainauguracao-de-brasilia-1960. Acesso em: 04 mai. 2012.

MOTTA, Marly Silva da. A nação faz cem anos: a questão nacional no centenário da independência. Rio de Janeiro: Fundação Getúlio Vargas - CPDOC, 1992. 